\title{
MANEJO DA IRRIGAÇÃO NA CULTURA DO CRISÂNTEMO EM VASO, CULTIVAR RAGE, CULTIVADO EM AMBIENTE PROTEGIDO
}

\author{
MARYZÉLIA F. DE FARIAS ${ }^{1}$, JOÃO C. C. SAAD ${ }^{2}$, ROBERTO L. VILLAS BÔAS ${ }^{3}$
}

\begin{abstract}
RESUMO: Dentre as dificuldades que os produtores têm encontrado ao adotarem o cultivo em ambiente protegido, destaca-se a falta de dados específicos sobre o uso racional da água e o desconhecimento da quantidade e do momento de irrigar. Esta pesquisa foi desenvolvida na propriedade de um produtor, no Distrito de Holambra II, região de Paranapanema - SP, em cultivos rotineiramente desenvolvidos pelo produtor, buscando melhor representatividade dos dados obtidos. O objetivo principal deste experimento foi identificar a tensão de água no solo que pudesse resultar em melhor qualidade comercial da cultivar de crisântemo "Rage", cultivado em vaso e mantido em ambiente protegido. O delineamento experimental foi o inteiramente casualizado, com duas repetições. Os tratamentos foram definidos por seis níveis de tensão de água: $-2 ;-3 ;-4 ;-6 ;-10$ e -30 kPa. Para cada tensão, foram calculadas a altura correspondente na coluna de mercúrio do tensiômetro, as lâminas e o tempo de irrigação. Os resultados obtidos demonstraram que a cultivar Rage obteve a maior porcentagem de vasos de alta qualidade (A1) no tratamento irrigado com a tensão de $-4 \mathrm{kPa}$. O tratamento irrigado, quando atingia $-30 \mathrm{kPa}$, resultou na menor porcentagem de vasos $\mathrm{A} 1$.
\end{abstract}

PALAVRAS-CHAVE: Dendranthema grandiflora, tensão de água no substrato, vaso.

\section{IRRIGATION SCHEDULE IN POT CHRYSANTHEMUM, CULTIVAR RAGE, GROWN IN GREENHOUSE}

SUMMARY: The most important difficulty that the producers have been found to adopt the cultivation in plastic greenhouses is the lack of specific data on the rational use of the water and informations about when and how much water apply. This research was developed in a farm in Paranapanema - SP, Brazil, with tradition in pot chrysanthemum grow. The main objective was to identify the soil water tension that could result in better commercial quality of chrysanthemum Rage, cultivated in pot and maintained in greenhouse. The treatments were defined for six levels of substrate water tension: $-2 ;-3 ;-4 ;-6 ;-10$ and $-30 \mathrm{kPa}$. The irrigation time was defined for each tension and also the equivalent height int the mercury column of the tensiometers. The obtained results showed that the cultivar Rage obtained the largest percentage of vases of high quality (A1) in the treatment irrigated with the soil water tension of $-4 \mathrm{kPa}$. The irrigated treatment when $-30 \mathrm{kPa}$ was reached resulted in the smallest percentage of vases A1.

KEYWORDS: Dendranthema grandiflora, substrate water tension, pot.

\footnotetext{
${ }^{1}$ Enga $^{\mathrm{a}} \mathrm{Agr}^{\mathrm{a}}$, Doutoranda, Departamento de Engenharia Rural, Faculdade de Ciências Agronômicas, UNESP, Botucatu - SP, 18603.970, Fone: (0XX14) 6824.7165, e-mail: maryzelia@fca.unesp.br

${ }^{2}$ Eng $^{\mathrm{o}}$ Agr $^{\mathrm{o}}$, Prof. Dr., Departamento de Engenharia Rural, FCA/UNESP, Botucatu - SP.

${ }^{3} \mathrm{Eng}^{\mathrm{o}} \mathrm{Agr}^{\mathrm{o}}$, Prof. Dr., Departamento de Recursos Naturais, FCA/UNESP, Botucatu - SP.

Recebido pelo Conselho Editorial em:13-5-2003

Aprovado pelo Conselho Editorial em: 17-12-2003
} 


\section{INTRODUÇÃO}

O crisântemo apresenta flores com grande aceitação de mercado sendo, por isso, considerado uma das plantas ornamentais de maior valor comercial. Entretanto, caracteriza-se por ser muito sensível a qualquer manejo inadequado em seu cultivo (BORNÁS \& URCULLU, 1953).

O cultivo do crisântemo em vaso ocupa o primeiro lugar no mercado nacional, respondendo por aproximadamente $80 \%$ da produção total. O segundo lugar é ocupado pelo cultivo chamado "de corte" (FERNANDES, 1996).

O consumo de água pelas espécies ornamentais cultivadas em estufas ainda é pouco conhecido. As culturas no interior das estufas estão em um ambiente diferente do externo. Nelas, o consumo de água é menor, principalmente pela atenuação que ocorre na densidade de fluxo da radiação solar incidente e da menor velocidade de renovação do ar junto às plantas (DALSASSO et al., 1997).

WREGE (1995), trabalhando com crisântemo em campo, encontrou uma demanda de água pela cultura de 296,42 mm para um tempo de cultivo de 90 dias. Embora esse trabalho encontre valor de consumo de água para a cultura do crisântemo, esse resultado não serve como parâmetro para a cultura quando cultivada em ambiente protegido.

O consumo de água pelo crisântemo envasado produzido em estufa pode ser estimado em função da área foliar e da evaporação do tanque reduzido (FURLAN, 1996).

A resposta das plantas ao potencial de água no solo tem sido estudada como forma de controle da irrigação, já que irrigações deficitárias refletem diretamente na redução da produtividade, enquanto irrigações excessivas prejudicam a qualidade da cultura.

O presente trabalho teve por objetivo identificar a tensão de água no solo (potencial matricial) que resulte em melhor qualidade comercial do crisântemo cultivado em vaso, cultivar Rage.

\section{MATERIAL E MÉTODOS}

O experimento teve início em 10 de abril de 2002, na propriedade de um produtor, no Distrito de Holambra II, município de Paranapanema, distante $256 \mathrm{~km}$ de São Paulo, cujas coordenadas geográficas são: latitude de $23^{\circ} 02^{\prime} 40^{\prime \prime} \mathrm{S}$, longitude $48^{\circ} 44^{\prime} 17^{\prime \prime} \mathrm{W}$ e $630 \mathrm{~m}$ de altitude. A estufa em arco estava localizada na direção leste-oeste, possuindo área de $6.000 \mathrm{~m}^{2}, 4 \mathrm{~m}$ de pé direito e cobertura plástica transparente de 150 micras.

A área experimental utilizada foi de $140 \mathrm{~m}^{2}$, dividida em seis parcelas, cada uma controlada por registro, tendo seis linhas com $5 \mathrm{~m}$ de comprimento, ficando os vasos a $0,05 \mathrm{~m}$ da superfície do solo, colocados sobre tijolos no espaçamento de $0,30 \times 0,30 \mathrm{~m}$, enquanto a tubulação do sistema de irrigação ficou diretamente sobre o terreno. Foram utilizados 118 vasos número $15(1,30 \mathrm{~L})$ por parcela, com um total de 708 vasos. Os vasos foram irrigados por gotejamento, utilizando-se de um gotejador tipo flecha por vaso, com uma vazão de $4,3 \mathrm{~L} \mathrm{~h}^{-1}$, na pressão de serviço de 10 mca. As lâminas de irrigação foram calculadas de acordo com cada tratamento (tensão) e, de posse da vazão, calculou-se o tempo de irrigação de modo que todos os tratamentos fossem irrigados, visando a elevar a umidade até o valor correspondente à capacidade de campo do substrato.

Utilizou-se a cultivar "Rage", que possui inflorescência de tamanho médio com coloração vermelha e pétalas simples.

O delineamento experimental foi o inteiramente casualizado, com duas repetições. Os tratamentos foram constituídos por seis níveis de tensão de água: $-2 ;-3 ;-4 ;-6 ;-10$ e $-30 \mathrm{kPa}$. Para cada tensão, foram calculados a altura correspondente na coluna de mercúrio do tensiômetro, as lâminas de água e o tempo de irrigação para cada tratamento (Tabela 1). 
Os tensiômetros utilizados neste experimento foram de dois tipos: com manômetro digital e com manômetro de mercúrio, fabricado no Departamento de Engenharia Rural da FCA - Câmpus de Botucatu - UNESP. Foram utilizados três tensiômetros por parcela, sendo dois digitais e um de mercúrio. A leitura da tensão foi realizada tomando por base o tensiômetro com manômetro de mercúrio que, quando comparado ao tensiômetro com manômetro digital, mostrou-se mais preciso, embora este último fosse de maior praticidade para o produtor. A profundidade de instalação dos tensiômetros foi de $7 \mathrm{~cm}$, e a altura da cuba de mercúrio em relação ao substrato foi de $12 \mathrm{~cm}$ para todos os tensiômetros.

TABELA 1. Tensões de água no substrato, altura da coluna de mercúrio, lâmina e tempo de irrigação para a cultivar de crisântemo "Rage".

\begin{tabular}{cccc}
\hline $\begin{array}{c}\text { Tensão } \\
(-\mathrm{kPa})\end{array}$ & $\begin{array}{c}\text { Altura da Coluna de Mercúrio } \\
(\mathrm{cm})\end{array}$ & $\begin{array}{c}\text { Lâmina de Irrigação } \\
(\mathrm{mL})\end{array}$ & $\begin{array}{c}\text { Tempo } \\
\text { (segundos) }\end{array}$ \\
\hline 2 & 3 & 52 & 45 \\
3 & 4 & 125 & 105 \\
4 & 5 & 139 & 120 \\
6 & 6 & 176 & 150 \\
10 & 9 & 202 & 170 \\
30 & 25 & 235 & 200 \\
\hline
\end{tabular}

O substrato utilizado nos vasos constituiu-se de mistura de solo (30\%), pó de xaxim $(30 \%)$ e casca de pínus (40\%), com densidade aparente de $0,54 \mathrm{~g} \mathrm{~cm}^{-3}$ e densidade das partículas do solo de $2,32 \mathrm{~g} \mathrm{~cm}^{-3}$.

Na Figura 1, apresenta-se a curva de retenção do substrato utilizado no experimento.

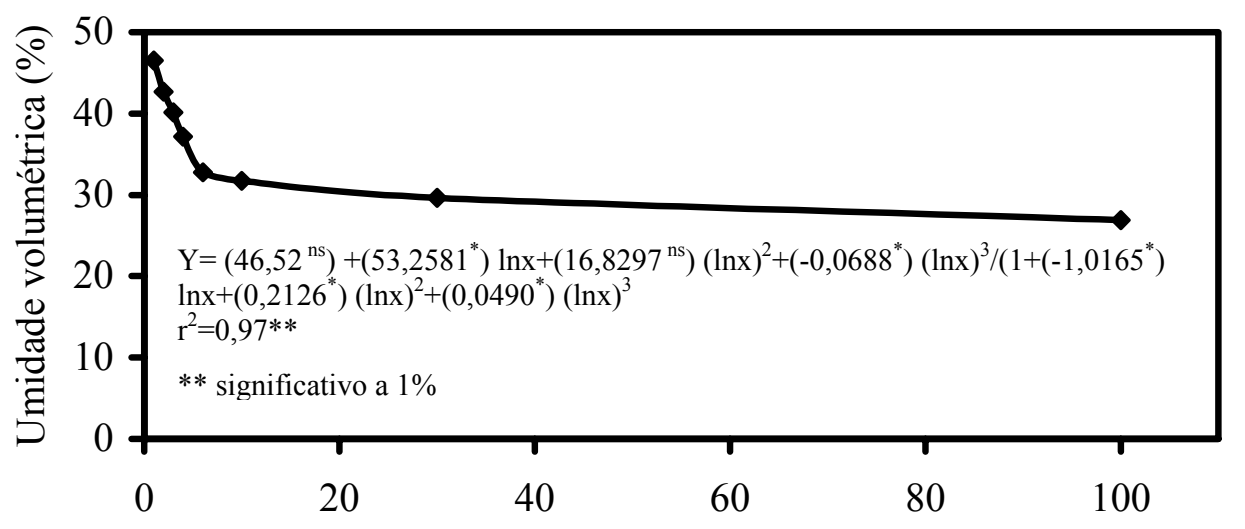

Tensão de água no substrato $(-\mathrm{kPa})$

FIGURA 1. Curva de retenção do substrato constituído de 30\% de solo, $30 \%$ de pó de xaxim e $40 \%$ de casca de pínus.

Os resultados foram avaliados por análise de regressão pelo programa computacional "Table Curve". Para a escolha da equação, foi considerado o gráfico que melhor ajustava os dados.

As plantas foram avaliadas de acordo com o padrão de qualidade exigido pelo mercado, sendo, para isso, levada em consideração a classificação adotada pelo produtor. Os produtos de qualidade A1 são constituídos por lotes formados com plantas de ótima qualidade, em que as plantas devem apresentar-se: isentas de pragas e doenças, com hastes firmes e com boa sustentação; bem formadas; 
com florescimento uniforme; todas com o mesmo estado de maturação e com coloração firme. As hastes não devem apresentar "ramos ladrões" laterais. O tamanho das plantas deve variar entre 23 a $35 \mathrm{~cm}$, mantendo, assim, uma proporcionalidade com o tamanho dos potes (MOTOS \& OLIVEIRA, $\mathrm{sd})$.

Foram analisados as tensões de água no substrato, a lâmina de água total e a média consumida, o comprimento da raiz, o peso seco e a qualidade das plantas.

\section{RESULTADOS E DISCUSSÃO}

A menor lâmina total consumida foi obtida com o tratamento irrigado com a tensão de $-10 \mathrm{kPa}$ (Tabela 2). Para SCATOLINI (1996), o potencial matricial inferior a $-40 \mathrm{kPa}$ para o crisântemo é suficiente para manter a cultura sempre bem suprida de água, não havendo déficit que possa prejudicar seu desenvolvimento ou que altere significativamente a evapotranspiração.

De acordo com FARIAS (2003), esse menor consumo de água na tensão de -10 kPa pode ser explicado em função de alguns parâmetros fisiológicos como a taxa de crescimento relativo (TCR), que representa a capacidade da planta em produzir material novo. A tensão de $-30 \mathrm{kPa}$ foi responsável, no crisântemo, pela maior TCR quando comparada com as tensões de -2; -3; -4 ; -6 e -10 kPa. SOUSA et al. (1999), citados por FARIAS (2003), afirmam que plantas que se desenvolvem sob condições de maior estresse têm maior capacidade adaptativa que aquelas que cresceram em condições de disponibilidade hídrica satisfatória.

TABELA 2. Tensões de água no substrato, número de irrigações, lâmina de água total consumida e lâmina de água média consumida para a cultura do crisântemo, cultivar Rage.

\begin{tabular}{cccc}
\hline $\begin{array}{c}\text { Tensões } \\
(-\mathrm{kPa})\end{array}$ & $\mathrm{N}^{\text {o }}$ de irrigações & $\begin{array}{c}\text { Lâmina de Água Total } \\
\text { Consumida } \\
(\mathrm{mm})\end{array}$ & $\begin{array}{c}\text { Lâmina de Água Média } \\
\text { Consumida } \\
\left(\mathrm{mm} \mathrm{dia}^{-1}\right)\end{array}$ \\
\hline 2 & 215 & 414,5 & 5,92 \\
3 & 113 & 291,2 & 4,16 \\
4 & 107 & 302,6 & 4,32 \\
6 & 121 & 324,8 & 4,64 \\
10 & 85 & 277,9 & 3,97 \\
30 & 61 & 291,4 & 4,16 \\
\hline
\end{tabular}

A análise de regressão apresentada na Figura 2 demonstra haver uma correlação entre as lâminas de água consumidas e as tensões. A tensão de $-2 \mathrm{kPa}$ foi o tratamento com o maior consumo de água em relação aos demais tratamentos.

Os tratamentos irrigados com as tensões de -4 e $-6 \mathrm{kPa}$ obtiveram o maior comprimento de raiz. As tensões de -2 e $-30 \mathrm{kPa}$ foram responsáveis pelo menor desenvolvimento de raiz, provavelmente em função da menor e maior freqüência de irrigação, respectivamente (Figura 3).

Quanto ao peso da matéria seca das raízes de crisântemo, os resultados demonstram uma boa correlação entre os tratamentos, com pouca variação entre as tensões (Figura 4). O tratamento irrigado com a tensão de $-30 \mathrm{kPa}$ apresentou o menor peso de raiz, o que, provavelmente, ocorreu em função do estresse hídrico sofrido pelo crisântemo nesse tratamento.

$\mathrm{Na}$ Figura 5, depreende-se que o tratamento irrigado com a tensão de $-30 \mathrm{kPa}$ apresentou o menor número de vasos $\mathrm{A} 1$, confirmando a importância de a planta não sofrer estresse hídrico. $\mathrm{O}$ ponto de máxima qualidade foi obtido com a tensão de $-4 \mathrm{kPa}$. 


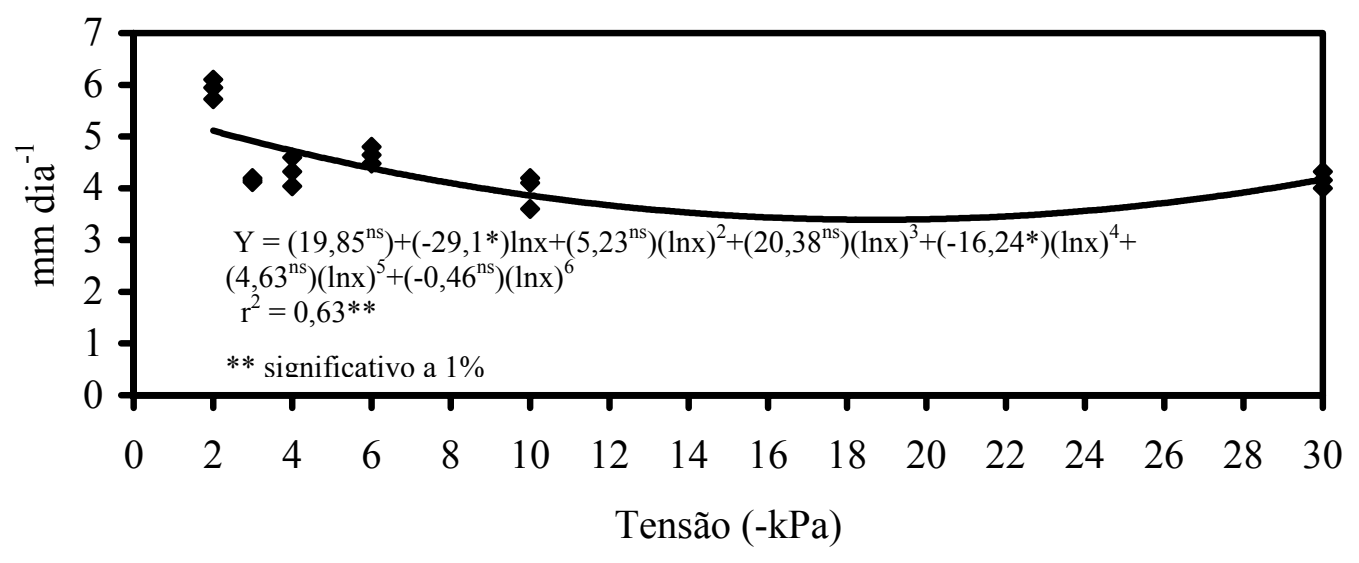

FIGURA 2. Lâmina de água consumida pela cultura do crisântemo, cultivar "Rage", em função da tensão de água no substrato.

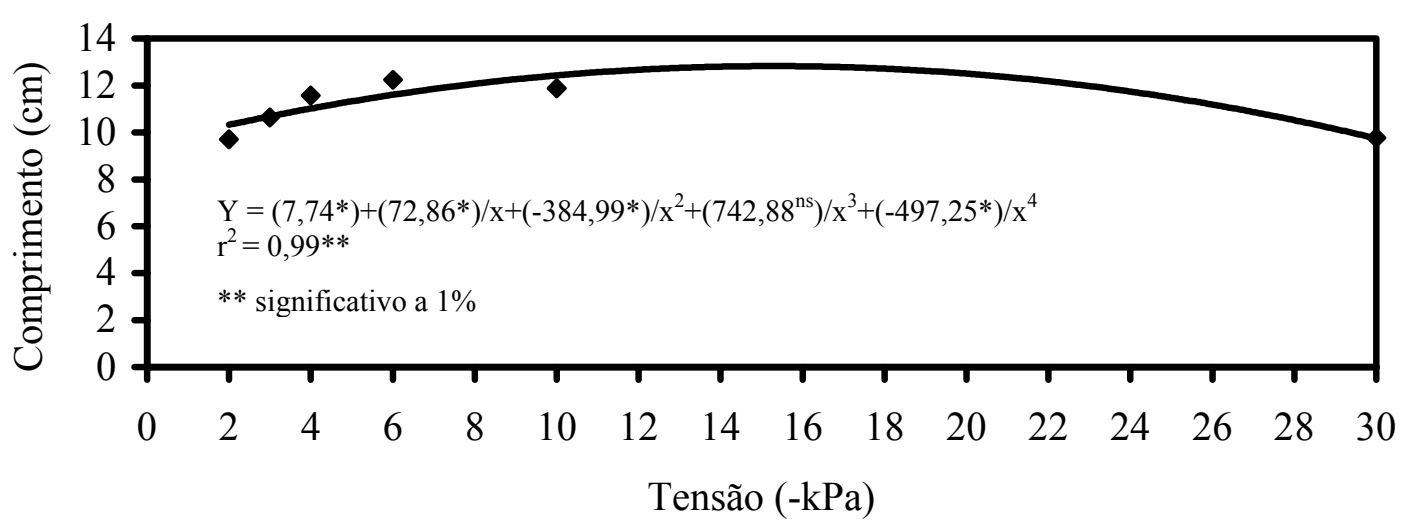

FIGURA 3. Comprimento de raiz para a cultivar de crisântemo "Rage", em função da tensão de água no substrato, aos 56 dias após o transplantio.

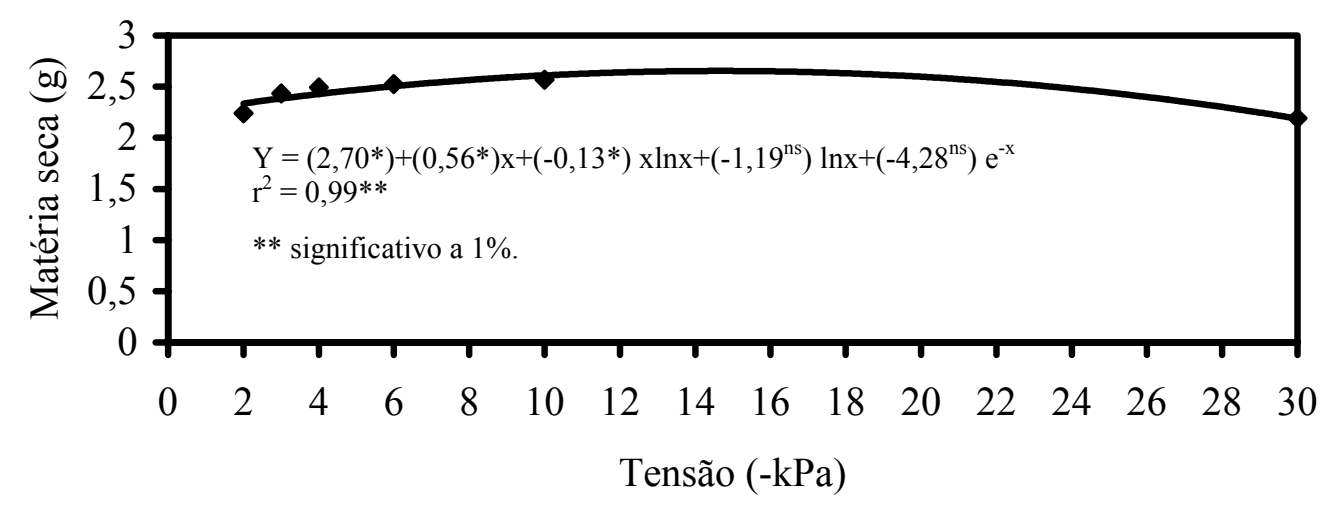

FIGURA 4. Peso da matéria seca de raiz para a cultivar de crisântemo "Rage", em função da tensão de água no substrato, aos 56 dias após o transplantio. 


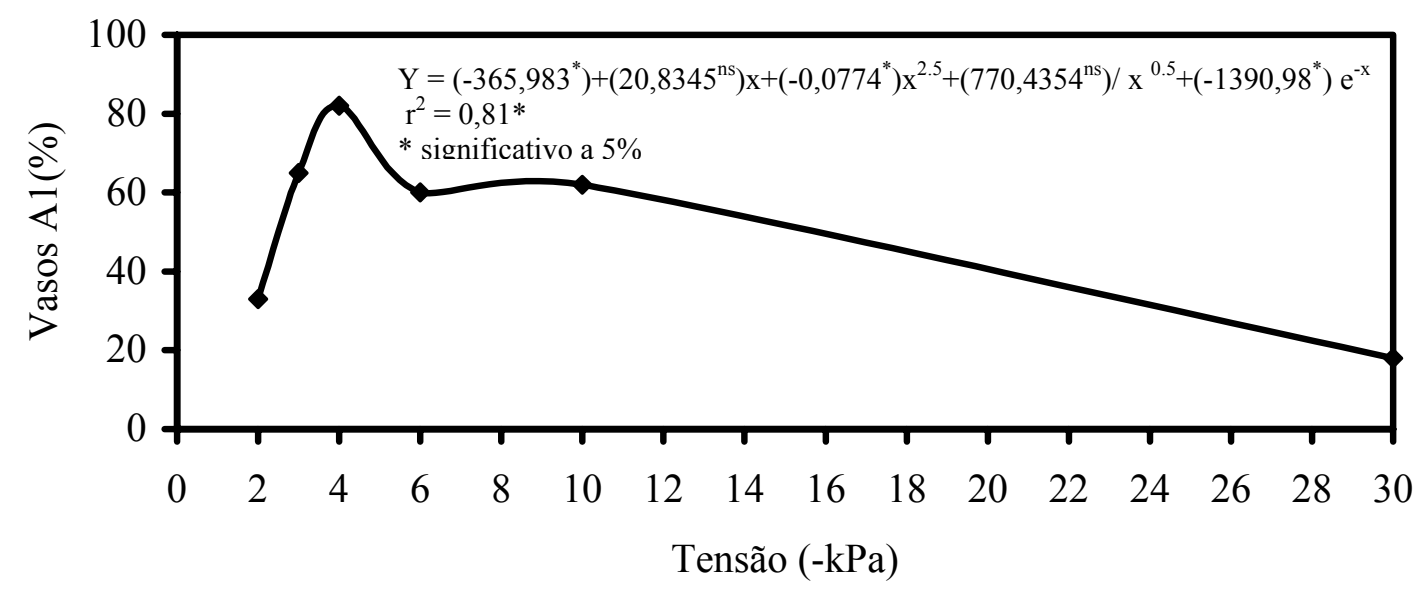

FIGURA 5. Porcentagem de vasos com qualidade A1 para a cultivar de crisântemo "Rage", em função da tensão de água no substrato, aos 56 dias após o transplantio.

\section{CONCLUSÕES}

A cultivar de crisântemo Rage obteve o maior número de vasos com qualidade A1 no tratamento irrigado quando a tensão da água no substrato atingia $-4 \mathrm{kPa}$.

$\mathrm{O}$ tratamento irrigado com a tensão de $-30 \mathrm{kPa}$ resultou na menor porcentagem de vasos de melhor qualidade (A1).

\section{REFERÊNCIAS BIBLIOGRÁFICAS}

BORNÁS, G.; URCULLU , D. Floricultura. Barcelona: Salvat Editores, 1953. 512 p.

DALSASSO, L.C.M.; HELDWEIN, A.B.; BURIOL, G.A.; SCHNEIDER, F.M.; STRECK, N.A.; DALMAGO, G.A. Consumo de água do tomateiro tipo salada em estufa plástica. Revista Brasileira de Agrometeorologia, Santa Maria, v.5 , p.61-7, 1997.

FARIAS, M.F. Manejo da irrigação na cultura do crisântemo (Dendranthema grandiflora) cultivado em vaso, em ambiente protegido. 2003. 83 f. Dissertação (Mestrado em Irrigação e Drenagem) Faculdade de Ciências Agronômicas, Universidade Estadual Paulista, Botucatu, 2003.

FERNANDES, A.L.T. Monitoramento da cultura do crisântemo em estufa através do uso de lisímetro e estação agrometeorológica automatizados. 1996. 96 f. Dissertação (Mestrado em Irrigação e Drenagem) - Escola Superior de Agricultura "Luiz de Queiroz", Universidade de São Paulo, Piracicaba, 1996.

FURLAN, R.A. Consumo de água pela cultura do crisântemo envasado, cultivar puritan, sob condições de estufa. 1996. 65 f. Dissertação (Mestrado em Irrigação e Drenagem) - Escola Superior de Agricultura "Luiz de Queiroz”, Universidade de São Paulo, Piracicaba, 1996.

MOTOS, J.R ; OLIVEIRA, M.J.G. de (Coord.). Classificação da qualidade. In: Produção de crisântemo em vaso. Holambra: Flortec, s.d. p.40-1.

SCATOLINI, M.E. Estimativa da evapotranspiração da cultura de crisântemo em estufa a partir de elementos meteorológicos. 1996. 70 f. Dissertação (Mestrado em Irrigação e Drenagem) - Escola Superior de Agricultura “Luiz de Queiroz,” Universidade de São Paulo, Piracicaba, 1996.

WREGE, M.S. Determinação do coeficiente de cultivo da cultura do crisântemo (Chrysanthemun morifloium Ramat. Var. Polaris amarelo). 1995. 101 f. Dissertação (Mestrado em Irrigação e Drenagem) - Universidade Estadual Paulista, Botucatu, 1995. 